\title{
Best Practices for Using Global Virtual Teams
}

Holt Zaugg

Brigham Young University, holt_zaugg@byu.edu

Randy Davies

BYU, randy.davies@byu.edu

Alan Parkinson

BYU, parkinson@byu.edu

Spencer Magleby

BYU, magleby@byu.edu

Follow this and additional works at: https://scholarsarchive.byu.edu/facpub

Part of the Curriculum and Instruction Commons

\section{Original Publication Citation}

Holt Zaugg, Randy Davies, Alan Parkinson, and Spencer Magleby, "Best Practices for Using Global Virtual Teams", TechTrends, July/August 2015, Volume 59, Number 4, 87-95

\section{BYU ScholarsArchive Citation}

Zaugg, Holt; Davies, Randy; Parkinson, Alan; and Magleby, Spencer, "Best Practices for Using Global Virtual Teams" (2015). Faculty Publications. 1630.

https://scholarsarchive.byu.edu/facpub/1630

This Peer-Reviewed Article is brought to you for free and open access by BYU ScholarsArchive. It has been accepted for inclusion in Faculty Publications by an authorized administrator of BYU ScholarsArchive. For more information, please contact ellen_amatangelo@byu.edu. 
Best Practices for Using Global Virtual Teams

Holt Zaugg, Brigham Young University (corresponding author)

Randy Davies, Brigham Young University

Alan Parkinson, Brigham Young University

Contact information for corresponding author (holt zaugg@byu.edu Phone 801-422-4178) 


\begin{abstract}
As global economies and interactions increase, there is a developing need for students to have a variety of cross-cultural experiences. Traditionally these experiences have occurred through study abroad experiences and internships. With the advent of virtual technologies global virtual teams are an opportunity to provide students with a cross-cultural experience. However, stakeholders need to be aware of their roles and responsibilities in such an endeavor.

This article discusses findings from a three-year study seeking to integrate global virtual teams into regular classrooms. The roles and responsibilities of institutions, faculty, and students are discussed in this article.
\end{abstract}

Keywords: global virtual teams, cross-cultural, virtual communication. 
Globalization influences business, commerce, and society at local and international levels (Ferraro, 2009, Morris, 2008). In an effort to prepare students to take advantage of and influence these global interactions, educational institutions provide cross-cultural exchange opportunities for students (Grandin, 2006, Grudzinski-Hall, Stewart-Gambino, Jellison and Weisman, 2007, Dobson et al., 2001; Wojciechowski \& Standridge, 2010). Traditionally these exchanges take the form of study abroad programs or internships with students travelling to foreign countries for varying lengths of time to interact at various levels with different cultures. Such opportunities help students to gain a greater understanding of the host culture, its people, and the influences of cross-cultural interactions. The advent of social media and virtual interactive technologies provides another opportunity for cross-cultural collaboration. While this opportunity does not provide the sights, sounds, and experiences of a study abroad program, it does provide the opportunity to learn from individuals in another culture while experiencing the challenges associated with global collaboration in a cost and time effective manner.

Integrating cross-cultural collaborations via Internet based technologies is not as simple as flipping a switch or clicking a button to allow the interactions to begin (Barczak, McDonough, \& Athanassiou, 2006; Poehler \& Schumacher, 2007). Ripple effects between stakeholders influence the decisions and actions at each level of the educational process. The interaction between institutions, faculty, and students influences the success of such initiatives.

This paper discusses the findings from a three-year study seeking to integrate global virtual teams into existing engineering courses. The results focus on the critical role of cultural influences exacerbated by technological interactions that affect such integration. The study sought to answer the question, in what ways can global virtual teams be successfully integrated into regular engineering classrooms? While this example refers specifically to the experience of 
engineering education, similar issues would be raised for stakeholders in any discipline seeking to provide a cross-cultural experience via global virtual teams using Internet communication technologies. Preparing for such issues facilitates the initial success and development of global virtual interactions.

\section{Method}

The research employed a design research model using a mixed methods approach for data collection. Over the three-year research cycle, as data and information accrued, the scope of the research expanded and refocused to better answer the research question. For example, during the first year, data collection was suspended during the second iteration of the advanced design course to develop a stronger focus and tools to use in the research. Time was taken to identify and condense indicators of global competence into a single document (Ball, et al. 2011). In addition, efforts were made to develop an instrument to assess the willingness of students to work with other cultures (Davies, Zaugg \& Tateshi, in press). Finally, using the identified competencies, lessons were developed to teach cultural and virtual communication principles best suited to global virtual $(\mathrm{GV})$ teams. The lessons were piloted in the second year using synchronous instruction and revised prior to the third year into an asynchronous format (please see http://byuipt.net/PGVT).

Over the three-year cycle, the research involved students registered in one of two engineering courses. The first course, an advanced design (AD) engineering course, provided instruction to students on how to use computer assisted design tools to make and evaluate mechanical models. The AD course was conducted twice in the first year and once (Fall semester) in the following two years. The AD course was taught on the Brigham Young University (BYU) campus with partner universities participating synchronously, using virtual 
communication tools, or asynchronously, with students viewing recorded lectures. As part of the coursework, students were required to work on a team, comprised of BYU students and partner university students, to complete a design assignment. In each iteration, all students were third or fourth year engineering students at their respective universities.

The second course was an engineering capstone (CAP) course. The course was an engineering program summary course where students were formed into a team and used their accumulated skills to solve a real-life engineering problem with business partners during the Fall and Winter semesters. A coach, who was either a university professor or an expert in industry, typically mentored students in the CAP course. In both years BYU students were partnered with National University of Singapore (NUS) students. Students from Pennsylvania State University (PSU) joined the research in the last year of the research study for the fall semester only. A summary of students participating in the course is shown in Table 1.

[Insert Table 1 about here]

As mentioned previously, data collection involved both quantitative and qualitative research methods. Pretest and posttest surveys were administered to each student in each iteration of each course. CAP students also completed a mid-year survey. While both NUS and PSU students participated in the second iteration of the CAP course, only BYU students were willing to participate in the research. As a result only BYU students participating in the second iteration of the CAP course were used in the research.

Depending on the iteration, year and course, GV team members were also interviewed and GV team meetings observed. In the first iteration of the AD course only BYU students were interviewed. In subsequent iterations, interviews were expanded to include international students, but the interviewees were restricted to team leaders and selected GV team partners. All BYU 
students, in each CAP course iteration, were interviewed. All interviews occurred near the end of each course with the exception of the second iteration of the CAP course. These students were interviewed midway through the course and at the end of the course. BYU coaches of the CAP courses were also interviewed to gain additional insights on team member performance and interactions.

During the research, observations of GV team meetings were changed. In the first iteration of the AD course, at lease one team meeting for each team was observed and recorded. However, resources did not allow for this intensity of observations to continue in subsequent iterations. In the first iteration of the CAP course, only two team meetings were observed, but, in the second iteration, with only one team participating, each team meeting was observed and recorded. Selected AD course lectures were observed in the first three iterations and all course lectures were observed in the final iteration. No CAP courses were observed. A summary of data collection methods for each course in each year is shown in Table 2.

\section{[Insert Table 2 About Here]}

\section{Findings}

Each iteration of the study added to the body of knowledge informing the researchers how GV teams may be best integrated into existing courses. These findings were combined into each subsequent iteration allowing for a refocusing and refinement of the research question and GV team practices. The findings focus on the responsibilities and accountability of three stakeholders. The stakeholders include the institution, the faculty, and the students. Although engineering courses were used for this study, it is felt that similar patterns would exist for other GV educational opportunities in other disciplines. 
Institution. Alignment and accountability were the two largest institutional issues involving this project. Alignment focused on the start-finish dates of school semesters as well as national holidays. Semester alignment required students at some universities to wait to begin while students at other universities had to catch-up on assignments. Since Brigham Young University (BYU) hosted this program, the other universities had to align their programs to fit BYU's schedule. For example, the University of British Columbia (UBC) students began their semester a week after BYU. Two or three make-up lectures were conducted to help students make up missed lectures and complete course requirements. In the case of Asian students, each lecture was posted on-line and students were able to view the lecture and seek additional help from project team members located at BYU. Although initially intended only for Asian students, Asian and non-Asian students referred to these posted lectures to gain a greater understanding of course content.

To accommodate the varied start times, the host professor allowed for "soft" due dates on assignments for the first month of the course. That is, local and remote students were allowed to submit class and lab assignments late for the first month without penalty. This adjustment gave all students the chance to catch up on assignments and work out team protocols to facilitate effective completion of course assignments. After the first month, all students were required to meet hard deadlines for assignment completion. It should be noted that for Asian students this compliance often meant losing one day of preparation due to the 14 hour time zone difference that spanned the International Dateline. In the CAP course students were granted a one-day differential to provide Asian students with the same allotted time to complete course assignments. For example, if an assignment deadline for BYU was Thursday at 9:00 AM, the NUS students had a Friday at 9:00AM to account for the time difference. 
Throughout the semester, holidays became somewhat problematic as the course and lecture schedule were focused on U.S. holidays. For example, BYU had a three-day holiday at the end of November corresponding to American Thanksgiving. However, UBC students missed a Monday lecture for the Canadian Thanksgiving celebrated a month earlier in October. Other partner universities had holidays unique to their own culture (e.g. Mexico's All Saints' Day celebrations). In planning, students and faculty had to develop "work-arounds" for these dates. Two solutions focused on BYU team members covering for remote team members during partner university holidays or partner university students working ahead prior to the holiday since the project was on a tight timeline. Some students also used the posted lectures to attend the class even though they were on holiday. In many cases remote students used the BYU holidays as a bonus day to help catch up or finish off team assignments. Patience and understanding were key factors as faculty and students informed one another of these cultural dates or other impending absences (i.e. students missing to attend family weddings, etc.). In interviews students indicated that this sharing and reminding of upcoming cultural holidays became instrumental in building trust among team members. Student reported competence on building and maintaining relationships of trust increased from moderate competence to competent or very competent by $31 \%$ and from competent to very competent by $8 \%$.

Issues of accountability focused on students committing to and following through on course assignments. Several approaches were taken. At BYU the global virtual component was simply added as part of the course requirement. At UBC, students were able to volunteer to attend the BYU lectures and complete a GVT project in place of a comparable project done in a similar local course. The University of Sao Paulo (USP) in Brazil registered students in a special projects course. Each of these approaches were effective because universities were able to 
integrate the project into local engineering programs, course tuition and fees were collected locally, and students were given course credit for a commensurate amount of course work. Less favorable approaches included students participating as part of a university club experience or attending because of a personal interest. In these cases the absence of a course grade and credit resulted in students not taking the GV course work as seriously. As a result not as great an effort was placed on the GV collaboration, resulting in reduced trust among team members. Ultimately these latter approaches were detrimental to team members who were taking the course for credit as not all team members could be depended upon to complete assignments. The for-credit students had to complete more work with fewer people.

Institutional efforts need to focus on alignment of institution and cultural calendars. Program adjustments that allow for time zone differences and start dates also need to be made. To increase student participation and buy-in, institutions need to offer program credit commensurate to the effort put into the course. Each of these activities help to streamline the activities of the course.

Faculty. In this case, as with many others cross-cultural projects, the global project began with faculty forming partnerships through friendships with faculty from other universities. As with previous research, the pre-existing relationship of trust and confidence with one another facilitated project development and implementation (Bergiel, Bergiel, \& Balsmeier, 2008; Prasad $\&$ Akhilesh, 2002). The engineering design course chosen for the global virtual teams had partnered with international counterparts on other projects (i.e. P.A.C.E.) where the students had worked on a common project and passed the project from one school to the next. During this research project, BYU and partner schools collaborated on the same project at the same time. As a result, the faculty members from each university met in regular, virtual meetings. 
In essence the faculty formed their own GV team. Meetings focused on the coordination of course assignments, activities, and course expectations. This GV interaction allowed faculty members from all schools to voice concerns, raise issues, and bring unique cultural issues to be discussed. While upcoming holidays were discussed, faculty members also considered alignment of software so all institutions had the same version of CAD software. When technical problems arose, these meetings became a time of collaboration to develop alternative solutions. The meetings also allowed for co-ordination of mid-term and final exam schedules and the project presentation, which was used as part of the final examination. The project presentation, used as part of the final exam, was marked by professors from all participating universities and members of industry associated with engineering. Since presentations were done and viewed from several remote locations, co-ordination prior to the final was critical.

The GV faculty meetings also provided time for clarification of cultural issues influencing course lectures and assignments. For example, in the first year of the research project a Mexican student asked why the BYU professor always started classes exactly on the hour instead of waiting for students to visit for 5-10 minutes before beginning instruction. The weekly faculty meetings allowed the Mexican faculty to explain this cultural practice that commonly occurred at his university. The faculty meeting became a place where the BYU professor understood the late arrival (indicated by a bleep during presentation) that the Mexican students were now present. It also allowed the Mexican professor the opportunity to instruct his students to be aware that the class was following the American protocol of starting instruction on time. Regular contact between faculty members provided a greater understanding for faculty that could then be passed on to students. 
Upon reflection for CAP course collaborations that did not work as effectively, one BYU professor stated that, given a second opportunity to coach such a team, he would contact the other coach and ask as many questions as possible to understand the capstone project at the other university. He went on to say that he would seek to develop a strong personal relationship with the NUS coach, as they had never met before. The action of seeking to establish, build, and maintain trust among faculty members working with students became a critical activity to the success of the program. In their seminal study, Jarvenpaa and Leidner (1999) initially defined the importance of this communication and trust building to ensure success among GV team members. Chen, Vogel, Zhang and Zhao (2009) indicated that, when such open knowledge sharing did not occur, especially when using virtual tools, positive trusting relationships were damaged. Unlike teams situated in the same location, GV teams had to plan for "social" interactions among team members either prior, during or after team meetings for trust building and maintaining to occur.

An additional concern of faculty was how to present additional cultural instruction to an already demanding course. Initially BYU faculty members, with international experience, were invited to make presentations as part of the course material. However, this proved problematic as regular course material had to be condensed or eliminated to make room for the additional lectures. There was also some concern regarding what content should be included in such lectures.

As core competencies needed to succeed on global virtual teams were identified and a curriculum of global competence was created, the content of these lessons changed (Deardorff, 2006; Hunter, White, \& Godbey, 2006). Multiple articles discussing global competencies were identified, compiled, and validated (Ball et al., 2011). The global competencies identified 
universal as well as discipline specific competencies. Objectives within this global curriculum were then identified as being feasible to be taught within the scope of a course using global virtual teams. From this general and specific cultural instruction was developed.

In the second year this instruction was presented in a synchronous manner to CAP course students. However, large time zone differences, placement into program requirements, alignment with CAP course instruction, and issues with credit assignment made this approach unwieldy. These materials were modified to an asynchronous format of 10 lessons with built-in assessments (please see http://byuipt.net/PGVT). These lessons were integrated into the lab portion of engineering courses. Students were able to complete the course content at a time convenient to their schedule. When compared to previous methods of instruction delivery, the asynchronous, imbedded approach to content delivery was the most effective for maintaining original course integrity while adding specific instruction to help students with cultural interactions and virtual communication issues. Interviews with and observations of students, indicated that students understood and implemented strategies taught by the course and mentioned cultural concepts that facilitated cross-cultural communications. Communication patterns, among teams who completed these lessons, were more intertwined with all team members instead of having teams segmented into sub-teams with a single line of communication. Shifts in self-reported competence indicated a $31 \%$ shift from moderate competence to competent and a $23 \%$ shift from competent to very competent.

As indicated in previous research these refinements in course delivery allowed instructors to use the correct technology in a manner that produced clear effective learning (Borko, Whitcomb \& Liston, 2009; Brandl \& Neyer, 2009). Course creators need to give consideration as to how instruction is presented. The content and activities in the course should build student 
confidence and increase their ability to transfer communication and interaction skills from one setting to another. It helps to build a virtual, cultural identity among team members that helps them identify and fulfill team roles (McNair, Paretti, \& Kakar, 2008). In this way faculty, working within their own GV team, help prepare students for both virtual and cultural interactions that will facilitate success in working on GV teams.

Students. Student interactions with one another were the primary concern in this research. Without face-to-face contact, oral and written communication became paramount (Zaugg, 2012). Strong common language skills (written and spoken) were essential and second language abilities were very helpful (Anawati \& Craig, 2006; Fruchter, 2003; Shachaf \& Hara, 2010). For example, in the first year of the study, one team required team meetings in Spanish and English because only a few team members spoke both languages fluently enough to conduct a full team meeting. In the last year, Korean and Chinese students adopted a format where the best English speaker would meet with the BYU team members to understand concepts and assignments. They would then relay expertise and information in their native language to local team members. While this reduced the effectiveness of the cultural interactions, it did clear up misunderstandings and helped students understand what needed to be done and when.

Teams with strong language abilities and cultural experience were more successful. In the final year Mexican students on one team indicated that a strong teambuilding component occurred when BYU students initially spoke Spanish during the GV team's first few meetings. Seeing that the BYU students were willing to try to speak the second language and were not as concerned about pronunciation and grammar as the whole communication, helped the Mexican students feel comfortable communicating with their English. They realized that the BYU 
students had the same patience with their English as the Mexicans did with BYU students' Spanish.

In other examples students from the National Taiwan University (NTU) commonly tried to learn and use English colloquial phrases. Students took time in each weekly meeting to just visit about non-engineering activities and tasks. At this time the NTU students would check the use of colloquial expressions (both written and spoken) of their communications. The BYU students would ask about cultural celebrations and activities. This approach created a greater cultural understanding, developed the Taiwanese students' English language abilities, and promoted a more open, trusting collaboration.

BYU students, who had lived in Brazil, not only were able to use Portuguese, but they also had an understanding of Brazilian cultural influences on work habits and punctuality. U.S. students wanted to start exactly on time and focus on the task at hand. However, Brazilian students were often a few minutes late to meetings as the start time for meetings was viewed as a guideline. Brazilians also wanted to develop relationships prior to working on the project by constantly visiting about non-engineering activities. Students on this team took a compromising approach where start time for meetings were flexible and visiting occurred during the team meetings. If discussions wandered too far or too long, team members were able to call for a refocus and move ahead with project assignments. This effort produced such strong understanding of each others abilities and developed trust so much that BYU students would contact their Brazilian counterparts for help with modeling rather than go to the local teaching assistants for the AD course.

In each of these examples students adapted their own cultural practices to that of remote team members. Doing so provided the opportunity to gain or improve cultural understandings. 
Student also participated in more open, collaborative team efforts. With this type of flexibility, students were able gain critical cultural insights as part of a meaningful engineering collaboration.

Finally, prior to entering a program with GV collaboration, students need to be made aware that working in a GV team setting increases the cultural and virtual levels of complexity to any task. Cultural and technical issues generally require more time and effort to solve than if the course work were all conducted locally with homogenous cultures. However, the cross-cultural interactions provide the opportunity for cultural layers to be added the final product. Instead of producing a product that fits a single culture, a product adaptable to many cultures is created. In addition, this level of complexity provides the opportunity for students to learn critical skills for future cultural and virtual interactions. For example, upon graduation, a former CAP student gained employment with an international firm. Her job was to help the company's South and Central American GV teams work and collaborate more effectively. Although her GV experience had not been as positive as hoped for, she commented that principles taught and skills learned while working on a GV team were immediately relevant to her job.

\section{Conclusion}

While GV team experiences do not have the same impact as cultural exchanges where students travel to foreign locations, they can provide meaningful cross-cultural experiences. For this to happen key cultural and stakeholder issues need to be addressed. Specific proactive steps may be taken to improve the start-up and running of such virtual courses.

Institutions. Alignment of institutional and cultural calendars is essential. Knowing and adapting semester start and finish times proves helpful. Providing for credit accommodations to 
increase student commitment and provide rewards for course completion are essential institution responsibilities.

Faculty. Where possible, GV teams should be started from pre-existing relationships. Faculty needs to make efforts to build and maintain trusting relationships while dealing with course concerns. Implementation of cultural and virtual instruction using appropriate technologies and exercises further assists student cultural and virtual learning. There needs to be allowance for assignment deadlines based on student start dates (from institutional calendars) and time zone differences that reduce the amount of time some students have to complete assigned tasks. Above all, faculty need to form their own GV team to discuss course and cultural issues and communicate uniform course expectations.

Students. Engaging students in second language training prior to or, perhaps, during such interactions would benefit the entire experience. Social interactions need to be planned into virtual communications to build trust and collaboration among team members. Students need to prepare to extend themselves beyond their cultural beliefs and values to understand the values and beliefs of their international counterparts. Taking the extra time to share and to care about team members facilitates collaborative efforts.

\section{Future Considerations}

Students preparing to engage in a study abroad experience could use GV teams to begin to build relationships with international partners, prior to the study abroad experience. Virtual contact with future collaborators just prior to the study abroad experience has the potential to enhance face-to-face, cultural interactions as students become familiar with one another. Prior virtual and cultural contact will help prepare students and faculty for cultural exchange opportunities. It advances the potential understandings and collaborations. Regardless of the 
discipline, using GV teams holds the promise to provide a meaningful cross-cultural experience or enhance and augment other cultural interactions.

\section{Acknowledgements}

The authors gratefully acknowledge the support provided by the US National Science Foundation grant EEC 0948997 that made this research possible. 
Table 1.

Number of participants in each course in each year by university and country.

\begin{tabular}{|c|c|c|c|c|c|c|}
\hline & \multicolumn{2}{|c|}{ 2009-2010 } & \multicolumn{2}{|c|}{ 2010-2011 } & \multicolumn{2}{|c|}{ 2011-2012 } \\
\hline & AD Fall & AD Winter & $\underline{\mathrm{AD}}$ & $\underline{\mathrm{CAP}}$ & $\underline{\mathrm{AD}}$ & CAP \\
\hline Brazil (USP) & 5 & - & 5 & - & 3 & - \\
\hline Canada (UBC) & 14 & - & 14 & - & 15 & - \\
\hline China (TU) & - & - & - & - & 3 & - \\
\hline Korea (HU) & - & - & - & - & 3 & - \\
\hline Mexico (UIA \& Toluca) & 9 & 6 & 9 & - & 6 & - \\
\hline Singapore (NUS) & - & - & - & & - & - \\
\hline Taiwan (NTU) & - & - & - & - & 3 & - \\
\hline USA (BYU) & 36 & 11 & 36 & 14 & 30 & 7 \\
\hline USA (WSU) & - & - & - & - & 3 & 5 \\
\hline Total Participants & 64 & 17 & 64 & 26 & 66 & 17 \\
\hline $\begin{array}{l}\text { Note. AD = Advance Design } \\
=\text { University of British Colu } \\
\text { Universidad Iberoamerican; } \\
\text { University; WSU = Wayne } S\end{array}$ & $\begin{array}{l}\text { urse; CAP } \\
\text { ia; TU= Tc } \\
\text { JS = Natio } \\
\text { te Universi }\end{array}$ & $\begin{array}{l}\text { Capstone cou } \\
\text { ji University; } \\
\text { I University of }\end{array}$ & $\begin{array}{l}\text { USP } \\
=\mathrm{Ho} \\
\text { gapor }\end{array}$ & $\begin{array}{l}\text { iversi } \\
\text { Univ } \\
\Gamma \mathrm{U}=\end{array}$ & $\begin{array}{l}\text { Sao P } \\
\text { ty; UI } \\
\text { onal T }\end{array}$ & $\begin{array}{l}; \text { UBC } \\
\text { an }\end{array}$ \\
\hline
\end{tabular}


Table 2.

Data collection method by course and year.

\begin{tabular}{|c|c|c|c|c|c|c|}
\hline & \multicolumn{2}{|c|}{ 2009-2010 } & \multicolumn{2}{|c|}{ 2010-2011 } & \multicolumn{2}{|c|}{ 2011-2012 } \\
\hline & $\underline{\text { AD Fall }}$ & $\underline{\mathrm{AD} \text { Winter }}$ & $\underline{\mathrm{AD}}$ & $\underline{\mathrm{CAP}}$ & $\underline{\mathrm{AD}}$ & $\underline{\mathrm{CAP}}$ \\
\hline Pretest Survey & $\mathrm{Y}$ & $\mathrm{Y}$ & $\bar{Y}$ & $\mathrm{Y}$ & $\bar{Y}$ & $\mathrm{Y}$ \\
\hline Posttest Survey & Y & $\mathrm{N}$ & Y & Y & $\mathrm{Y}$ & Y \\
\hline Mid-term Survey & Y & $\mathrm{N}$ & $\mathrm{N}$ & $\mathrm{Y}$ & $\mathrm{N}$ & Y \\
\hline Course Observation & Y & $\mathrm{Y}$ & Y & $\mathrm{N}$ & Y & $\mathrm{N}$ \\
\hline GV Team Meeting Observation & Y & $\mathrm{N}$ & Y & Y & $\mathrm{N}$ & Y \\
\hline GV Team Member Interview & Y & $\mathrm{N}$ & Y & $\mathrm{Y}$ & Y & $\mathrm{Y}$ \\
\hline Instructor/Coach Interview & Y & $\mathrm{N}$ & $\mathrm{N}$ & $\mathrm{Y}$ & $\mathrm{N}$ & $\mathrm{Y}$ \\
\hline
\end{tabular}

Note. $\mathrm{AD}=\mathrm{Advance}$ Design course $\mathrm{CAP}=$ Capstone course 
Anawati, D., \& Craig, A. (2006). Behavioral Adaptation Within Cross-Cultural Virtual Teams. IEEE Transactions on Professional Communication, 49(1), 44-56. doi: 10.1109/TPC.2006.870459.

Ball, A., Zaugg, H., Davies, R., Tateishi, I., Parkinson, A., Jensen, C. G., \& Magleby, S. (2011). Identification and validation of a set of global competencies for engineering students. International Journal for Engineering Education, 28(1), 1-13.

Barczak, G., McDonough, E., \& Athanassiou, N. (2006). So you want to be a global project leader? Research-Technology Management, 3449(3), 28-35. doi:10.1109/EMR.2006.261382

Bergiel, Blaise, J., Bergiel, Erich, B., \& Balsmeier, P. W. (2008). Nature of virtual teams: a summary of their advantages and disadvantages. Management Research News, 31(2), 99110. doi: $10.1108 / 01409170810846821$.

Borko, H., Whitcomb, J., \& Liston, D. (2009) Wicked problems and other thoughts on issues of technology and teacher learning, Journal of Teacher Education, 60, 3-7.

Brandl, J., \& Neyer, A. (2009). Applying cognitive adjustment theory to cross-cultural training for global virtual teams. Human Resource Management, 48(3), 341- 353. doi: 10.1002/hrm.20284.

Chen, Z., Vogel, D., Zhang, X., \& Zhao, D. (2009). Encouraging Knowledge Sharing in Global Virtual Teams: The Interaction Effect of Individual Difference and Perceived Sharing Benefits. Proceedings of the 42nd Hawaii International Conference on System Sciences, 110. 
Deardorff, D.K. (2006) Indentification and assessment of intercultural competence as a student outcome of internationalization, Journal of Studies in International Education, 10, 241-266.

Dobson, M. W., Pengelly, M., Sime, J.-A., Albaladejo, S. A., Garcia, E.V., Gonzales, F., \& Maseda, J. M. (2001). Situated learning with co-operative agent simulations in team training. Computers in Human Behavior, 17, 547-573.

Ferraro, G.P. (2006). The cultural dimensions of international business. Pearson Prentice Hall, Upper Saddle River.

Fruchter, R. (2003). Multi-Cultural Dimensions and Multi-Modal Communication in Distributed, Cross-Disciplinary Teamwork. The International Journal of Engineering Education, 19(1), 53-61.

Grandin, J. M. (2006). Preparing engineers for the global workplace. Engineering Education, 1(1).

Grudzinski-Hall, M., Stewart-Gambino, H. W., Jellison, K. L., \& Weisman, R. N. (2007). Engineering students in a global world: Lehigh university's global citizenship program. Online Journal for Global Engineering Education, 2(1), 1-8.

Hunter, B., White, G.P, \& Godbey, G.C. (2006) What does it mean to be globally competent? Journal of Studies in International Education, 10, 267-285.

Jarvenpaa, S.L. \& Leidner, D.E. (1999) Communication and trust in global virtual teams, Organizational Science, 10, 791-815.

McNair, L. D., Paretti, M. C., \& Kakar, A. (2008). Case Study of Prior Knowledge: Expectations and Identity Constructions in Interdisciplinary, Cross-cultural Virtual Collaboration. International Journal of Engineering Education, 24, 386-399. 
Morris, S. (2008). Virtual team working: Making it happen. Industrial and Commercial Training Journal, 40(3), 129-133. doi: 10.1108/00197850810868612. Rev

Poehler, L., \& Schumacher, T. (2007). The virtual team challenge: Is it time for training? PICMET '07 - 2007 Portland International Conference on Management of Engineering \& Technology, IEEE, 2205-2211. doi:10.1109/PICMET.2007.4349552

Prasad K, \& Akhilesh, K. B. (2002). Global virtual teams: What impacts their design and performance? Team Performance Management, 8(5/6), 102-112.

Shachaf, P., \& Hara, N. (2010). Behavioral complexity theory of media selection: a proposed theory for global virtual teams. Journal of Information Science, 33(1), 63-75. doi: 10.1177/0165551506068145.

Wojciechowski, J., \& Standridge, C. (2010). The mutual re-enforcement of curricular education and co-operative education: A case study. Proceedings of the American Society for Engineering Education Annual Conference, 1-9.

Zaugg, Holt (2012). Communication Patterns Among Members of Engineering Global Virtual Teams (Doctoral dissertation). Brigham Young University, Provo, Utah. 